\title{
Use of Salt-Tolerant Plants and Halophytes as Potential Crops in Saline Soils in China
}

\author{
Jianrong Guo*, Ming Du, Chaoxia Lu and Baoshan Wang* \\ Shandong Provincial Key Laboratory of Plant Stress, College of Life Science, Shandong Normal University, Ji'nan 250014, Shandong, China
}

*Corresponding author: Jianrong Guo \& Baoshan Wang, Shandong Provincial Key Laboratory of Plant Stress, College of Life Science, Shandong Normal University, N0.88 East of Wenhua Road, Ji'nan, Shandong, China.
Received Date: May 30, 2020

Published Date: June 15, 2020

\begin{abstract}
Soil salinity affects approximately 800 million hectares of arable lands worldwide. As soil salinization increases and farmland decreases globally due to climate change, irrigation and urbanization, a big challenge is to balance the reducing of soils areas for crop cultivation and the increasing of requirement of food and energy. It is considered as a desirable and sustainable strategy to utilize the saline soils by cultivating the salt-tolerant crop varieties or halophytes for agricultural usage. The cultivation of salt-tolerant plants on saline land has obtained a more and more increasing of interest. In the past a few decades, a lot of work has been done in the utilization of salt-tolerant plants and halophytes for agriculture usage in saline soil in China. The usage value according to the food, vegetables supply, saline land remediation, bioenergy production, and other economic value were briefly summarized. Furthermore, a better method to develop and utilize of saline land and the valuable information for future investigation of saline land were provided. This information is helpful for utilization of salt tolerant plants and halophytes in the sustainable development of saline land worldwide.
\end{abstract}

Keywords: Saline soils; Salt-tolerant crops; Halophyte; Application

\section{Introduction}

As one of the major abiotic stresses, salinity severely inhibits plant growth and development, leads to crop yield loss and plant ecosystem deterioration worldwide [1,2]. Sodium chloride is considered to be the most component that causing salinization and is the widespread salt that existing in saline soils [3]. UP to now, almost $10 \%$ of the land area and $50 \%$ of the irrigated soils area was affected by salinity presence $[1,4]$. In addition, the degree of soil salinization is still intensified due to natural and human factors such as irrational irrigation. Simultaneously, the agricultural land has declined due to the industrialization, the urban development, and the habitat need with the rapid increase of population [5]. Therefore, developing strategies to make use of saline land will be crucial for addressing the problem of insufficient farmland and meeting the challenge of providing food security for the projected global population of 9.3 billion people by 2050. It is considered as a desirable and sustainable strategy to plant the salt-tolerant crop varieties and halophytes for the agricultural usage of saline soils.

In general, the growth and the reproduction of crops were severely inhibited when they grow in saline environments [6], even died in heavily saline soils. 99.13 million hectares of saline-alkali land are present in China, accounting for about $12 \%$ of the world's saline-alkali land, and more than 20 million hectares of land are considered to be saline, among which $20 \%$ are distributed in cultivated lands [7]. Many works have been done in getting a better and more efficient way to use of the salinized land by biological methods in China. In the present paper, applied and potential plants that could grow on saline land and with economic and application value will be discussed, which will provide an insight understanding and application reference for improving and using the saline soils for agriculture. 


\section{Discussion}

There are about 420 halophyte species and more than 1000 salt-tolerant plants in China. In the current, a wide range of applications could be implemented according to the salt-tolerant plants and halophytes. Up to now, more than 100 species of the salt-tolerant plants and halophytes have been applied for improving saline lands in China. They could be used as food, such as the salt-tolerant wheat (Dekang 961, Shanrong 3), quiona, and sorghum; vegetables, such as Suaeda salsa, Salicornia bigelovii, and Ice plant (Mesembryanthemum crystalinum L.); forage, such as Atriplex triangularis, sweet sorghum, and wild soybean (Glycine soja Sieb. et Zucc.); fruits, such as winter jujube (Ziziphus jujuba cv. Dongzao), and $\mathrm{Ni}^{-}$ traria tangutorum; medicine, such as Glycyrrhiza uralensis Fisch, Apocynum venetum, and flower plant such as Limonium sinense. And bioenergy is considered as a renewable new energy.

With the rapid economy expansion, the demand for energy is sustaining insatiable. Bioenergy such as ethanol is selected as a new alternative energy source to meet the global requirement. In addition, to avoid the completion of food and farmland for people in China, the bioenergy is allowed to produce only in marginal soils such as saline soils by culturing the energy crops with higher salt-tolerant ability such as sweet sorghum, hybrid pennisetum, Manihot esculenta, and sugar beet $[8,9,10]$. Sweet sorghum with high salt tolerance, photosynthesis, high biomass and sugar content in the stem is widely planted in saline soil to be a suitable crop to produce the food, the animal feed, good liquor-making raw materials and bioethanol $[11,12]$.

Halophytes could grow under extreme salt conditions with highly salt-tolerant ability, evenly at sea salt level [13]. As the precious plant resources with high applicable value, halophytes have been obtained more and more attentions by scientists [14]. For instance, to remediate the saline soils by culturing halophytes, preventing salt back to the soil surface, and removing salt from the soils that reducing salt content [5]. In addition, halophytes also have many economic values, for example, some of them could be used as vegetables, fodder and fruit $[15,16]$. Even some of the halophytic vegetables such as Suaeda salsa could be irrigated using seawater or grown in the intertidal zone [17]. It could be providing gourmet vegetables using seawater and meet the shortage of freshwater resources in the world [18]. Furthermore, halophytes have other usage, Suaeda salsa could be used to produce oil due to the abounded content of unsaturated fatty acid in their seeds $[19,20]$. Halophytes could provide abounded salt-tolerant genes for studying the salt tolerance mechanism and obtain the genetically modified salt-tolerant crops. Perhaps, the problem of "less land for more population" in the developing countries could be solved by planting salt-tolerant plants and halophyte on the saline soils and provide economic benefit and could meet the problem of the restricted agricultural land resources [21,22].

\section{Conclusion}

With the increasing of the saline areas and the degrading of the arable soils in the world, we face the problem of how to balance the reducing of farmland and the increasing of the requirement of food and energy. The growth, development and reproduction of all crops are severely inhibited by saline soils. While some of the salt-tolerant plants can grow in the saline conditions, which could utilize the saline soils by culturing salt-tolerant plants and provide us food, vegetables, fruits, animal forage, flowers and bioenergy. This will solve the contradiction between the increase in population and the decrease in cultivated land area, and at the same time, provide a better method to develop and utilize of saline land. Therefore, screening more salt-tolerant plant and halophytes with high potential value in agriculture is an urgent task.

\section{Acknowledgement}

None.

\section{Conflict of Interest}

No conflict of interest.

\section{References}

1. Ruan C, Silva JATD, Mopper S, Qin P, Lutts S (2010) Halophyte improvement for a salinized world. Crit Rev Plant Sci 29(6): 329-359.

2. Guo J, Dong X, Han G, Wang B (2019) Salt-enhanced reproductive development of Suaeda salsa L. coincided with ion transporter gene upregulation in flowers and increased pollen $\mathrm{K}+$ content. Front Plant Sci 10: 333 .

3. Yang Y, Guo Y (2018) Elucidating the molecular mechanisms mediating plant salt-stress responses. New Phytol 217(2): 523-539.

4. Riadh K, Wided M, Hanswerner K, Chedly A (2010) Responses of halophytes to environmental stresses with special emphasis to salinity. Adv Bot Res 53: 117-145.

5. Shabala S (2013) Learning from halophytes: physiological basis and strategies to improve abiotic stress tolerance in crops. Ann Bot 112(7): 1209-1221.

6. Onyemaobi I, Liu H, Siddique KHM, Yan G (2017) Both male and female malfunction contributes to yield reduction under water stress during meiosis in bread wheat. Front Plant Sci 7: 2071.

7. Li L, Zhao Y, Han G, Guo J, Meng Z, et al. (2020) Progress in the Study and Use of Seawater Vegetables. J Agric Food Chem 2020.

8. Riveraburgos LA, Volenec JJ, Ejeta G (2019) Biomass and Bioenergy Potential of Brown Midrib Sweet Sorghum Germplasm. Front Plant Sci 10.

9. Wang D, Guo J, Liu X, Song J, Chen M, et al. (2014) Effects of cultivation strategies on hybrid pennisetum yield in saline soil. Crop Sci 54(6): 2772-2781.

10. Skorupa M, Golebiewski M, Kurnik K, Niedojadlo J, Kesy J, et al. (2019) Salt stress vs. salt shock - the case of sugar beet and its halophytic ancestor. BMC Plant Biol 19(1): 57

11. Yang Z, Li J, Liu L, Xie Q, Sui N (2020) Photosynthetic regulation under salt stress and salt-tolerance mechanism of sweet sorghum. Front Plant Sci 10: 1722 .

12. Sui N, Yang Z, Liu M, Wang B (2015) Identification and transcriptomic profiling of genes involved in increasing sugar content during salt stress in sweet sorghum leaves. BMC Genomics 16(1): 534-534. 
13. Song J, Wang B (2015) Using Euhalophytes to understand salt tolerance and to develop saline agriculture: Suaeda salsa as a promising model. Ann Bot 115(3): 541-553.

14. Guo J, Li Y, Han G, Song J, Wang B (2018) NaCl markedly improved the reproductive capacity of the euhalophyte Suaeda salsa. Funct Plant Biol 45(3): 350-361.

15. Bustan A, Pasternak D, Pirogova I, Durikov M, Devries TT, et al. (2005) Evaluation of saltgrass as a fodder crop for livestock. J Sci Food Agr 85(12): 2077-2084.

16. Tardio J, Pardodesantayana M, Morales R (2006) Ethnobotanical review of wild edible plants in Spain. Bot J Linn Soc 152(1): 27-71.

17. Atzori G, Nissim WG, Caparrotta S, Masi E, Azzarello E, et al. (2016) Potential and constraints of different seawater and freshwater blends as growing media for three vegetable crops. Agr Water Manage 176: 255262.
18. Zhong S, Geng Y, Qian Y, Chen W, Pan H (2019) Analyzing ecosystem services of freshwater lakes and their driving forces: the case of Erhai Lake, China. Environ Sci Poll Res 26(10): 10219-10229.

19. Zhao Y, Ma Y, Duan H, Liu R, Song J (2019) Traits of fatty acid accumulation in dimorphic seeds of the Euhalophyte Suaeda salsa in saline conditions. Plant Biosyst 153(4): 514-520.

20. Guo J, Suo S, Wang BS (2015) Sodium chloride improves seed vigour of the euhalophyte Suaeda salsa. Seed Sci Res 25(3): 335-344.

21. Gu C, Xu S, Wang Z, Liu L, Zhang Y, Deng Y, et al. (2018) De novo sequencing, assembly, and analysis of Iris lactea var. chinensis roots' transcriptome in response to salt stress. Plant Physiol Biochem 125: 1-12.

22. Zhao KF, Li FC (1999) Halophytes in China. Bulletin of Botany 16(3): 201-207. 